\title{
The connective tissue in livers of children
}

\author{
M. L. GHOSH AND J. L. EMERY \\ From the Department of Haematology, Barnsley Hospital Group, Barnsley, and \\ the Department of Pathology, Children's Hospital, Sheffield
}

SYNOPSIS The amount of connective tissue present, relative to the amount of parenchymal tissue, has been assessed in a random series of 200 livers from children dying from non-hepatic disease. The amount of connective tissue in the left liver is approximately twice that in the right liver. The connective tissuein both lobes progressively diminishes during childhood but at all times remains higher than that in adults.

Increased amounts of connective tissue in the liver in children is probably non-specific and related to the degree and duration of shock and hypoxia in the immediate postnatal period.

The liver consists of two physiological lobes with the gallbladder at the junction (Cantlie, 18971898; Mall, 1906).

In the foetus the left liver receives most of its blood supply direct from the placenta, which source is cut off suddenly at birth. This is liable to produce asymmetrical disease of the liver in infancy (Emery, 1955), and intrauterine foetal disease produces more effects on the right liver than the left (Gruenwald, 1949; Emery, 1963).

The present study was carried out to quantitate the amount of connective tissue in the left and right lobes of infants and to make some assessment of its importance.

\section{Material and Methods}

The routine procedure at the Sheffield Children's Hospital has been to take controlled sections from the left and right livers. Paired sections of livers from over 5,000 necropsies were available, filed consecutively, and from these a series of 2,000 consecutive liver sections were drawn randomly.

An independent person surveyed the post-

Received for publication 11 March 1970. mortem protocol and any liver in which any pathological liver lesions had been noted was excluded, as were stillbirths and children dying within 24 hours of birth. The remaining 200 sections were then quantitatively assessed. The person doing the assessment had no knowledge of the age or history of the child.

The slides, stained by Masson's trichrome, were projected at constant magnification. The number of squares covered by the connective tissue within a total squared field was counted. Five random fields were surveyed and estimated. A preliminary reproducibility test revealed that the error of the method of assessment appeared to be consistently less than $2 \%$.

The proportion of connective tissue was plotted against postnatal age and the mean, standard deviation, and percentiles were worked out for each age group and each lobe.

To assess the possible pathological significance of differences of connective tissue content between the left and right lobes, two groups of cases were analysed: those which showed a difference of greater than $100 \%$ between the connective tissue in the left and right lobes and those cases in which the difference was less than $15 \%$.

Blocks were studied in exactly the same way from 10 adults not dying of liver disease. 


\section{Results}

The mean and percentile values of the connective tissue are presented in Figure 1. The connective tissue is greater in the left liver than in the right liver throughout the age studied. No difference was seen in the left and right lobes of the 10 adult livers.

Connective tissue constituted over $5 \%$ of the section surface in the left liver until the age of 6 months and that in the right liver above $3.5 \%$. In $18 \%$ of livers the difference between the left and right was over $100 \%$, being greater in the left than the right in $90 \%$ of livers.

The connective tissue content of the livers in infants is considerably greater than in adults. Levels for the adults were all below $2.5 \%$. Not one of the livers from the children dying before the age of 10 years was below $2.5 \%$.

There is a progressive diminution in the proportion of connective tissue in both lobes and also a diminution in the difference between the quantities in the left and right lobes, with increasing age. It would seem that this change continues until about 12 years of age when the connective tissue content becomes the same as in the adult liver.

The livers from two children in this series are shown in Figures 2 and 3. Both of these children died at 5 weeks; one had a liver containing $11.8 \%$ in the right and $29.3 \%$ fibrous tissue in the left, and in the second case the corresponding levels were $5.8 \%$ and $6.9 \%$.

CASE 1

This child was born at 38 weeks by Caesarean section for placenta praevia with haemorrhage from a woman who had hypertension and oedema. At birth $(2,780 \mathrm{~g})$ the child was shocked and did not breathe for several minutes. He became jaundiced on the second day and did not pass meconium and vomited bile-stained fluid. A laparotomy was carried out and an intestinal atresia repaired. The child's condition remained relatively satisfactory for several days and then his condition deteriorated steadily to death at 3 weeks.

\section{CASE 2}

This child was born at term, the sixth child of a healthy woman. The child weighed only $1,800 \mathrm{~g}$ but was active and apparently normal for its first six weeks after birth. He then acquired a staphylococcal infection with otitis media and was found dead in his cot at 7 weeks. Necropsy revealed an acute bronchiolitis, otitis media, and mastoiditis growing staphylococci.

The left and right lobes of these two infants are shown in Figs. 2 and 3 where the differences between the fibrous tissue in the lobes and the two cases will be obvious. In Figs. 4 and 5 are

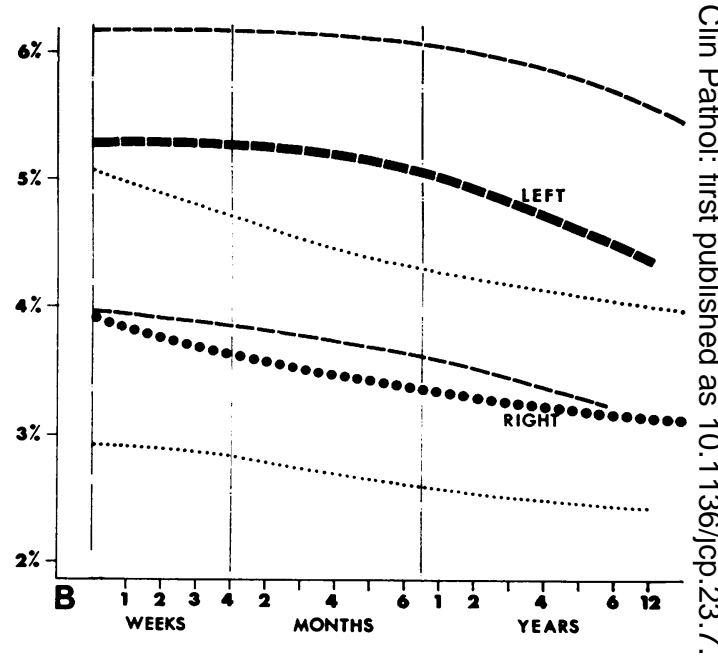

Fig. 1 The amount of connective tissue, expressed as a percentage of the section surface, in the left and right lobes of the liver in infants. The interrupted line shows results for the left lobe and dotted line for the $\overrightarrow{0}$ right lobe with the 10th and 90th percentiles of each? indicated in lighter lines.

shown the costochondral junctions from these two children.

\section{Discussion}

Many organs in the foetus contain much un-음 differentiated mesenchymal tissue. With growth of the organ the relative amount of connective tissue to parenchymal tissue diminishes and birth is simply one incident in this developing sym-ô phony, each organ having its own pattern of $\overline{0}$ development. The liver differs from other organs, such as the pancreas, in that through the lattero part of gestation its connective tissue is very $₹$ active haemopoietically. This decreases near을 term and dramatically diminishes after birth. It $\supset$ is thus not possible to project the present study? into the livers of stillborns of children dying at $\bar{N}$ different stages of gestation due to the virtual impossibility of assessing the amount of con- $\tilde{N}$ nective tissue in such livers.

The reasons for the relatively larger amounts of connective tissue in the left as distinct from the right liver are probably the same as those which ${ }_{\Phi}$ account for the degenerative changes frequently $\stackrel{?}{-}$ seen in the left lobe of the liver in the newborn, 0 that is, the sucden cutting off of the placental $\bar{P}$ blood flow through the left liver (Emery, 1952). The amount of connective tissue found in indi- $\frac{\overrightarrow{\mathbb{Q}}}{2}$ vidual livers is probably a reflection of excessive $\frac{\square}{0}$ involution of the parenchymal tissue of the left liver, probably related to circulatory shock in the 0 infant around the time of birth.

Such changes seem to be the principal factors 흘 

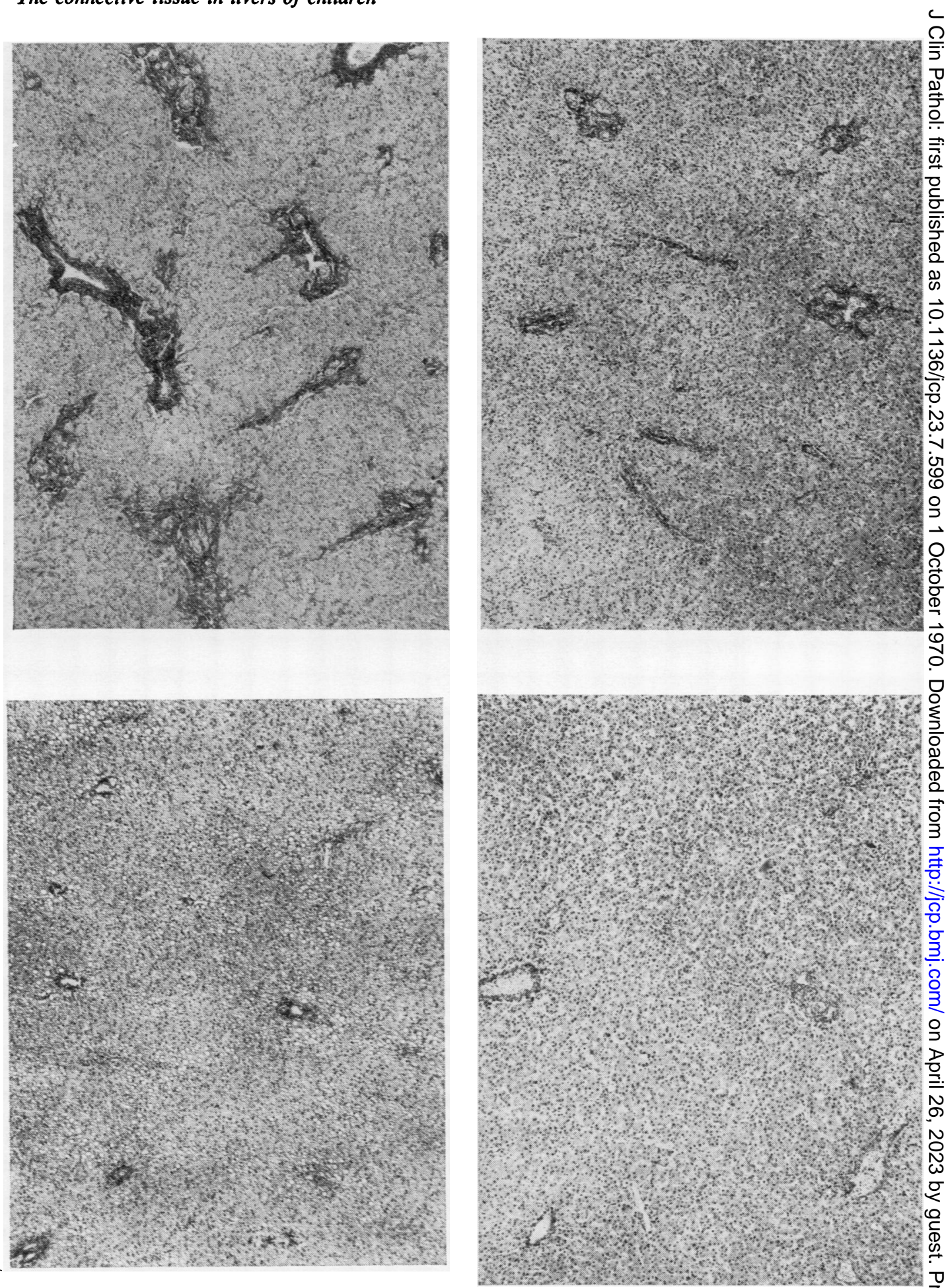

Fig. 2 Section of the left (top) and right (bottom) lobes of the liver from case 1 (stained Van Gieson $\times 60$ ). The sections show the relative connective tissue elements. Also note the fatty changes in the right liver compared with the left. This is probably related to the relatively increased metabolic importance of the right lobe at this particular age.

Fig. 3 Section of the left (top) and right (bottom) lobes of the liver from case 2 (stained Van Gieson $\times 60$ ). 


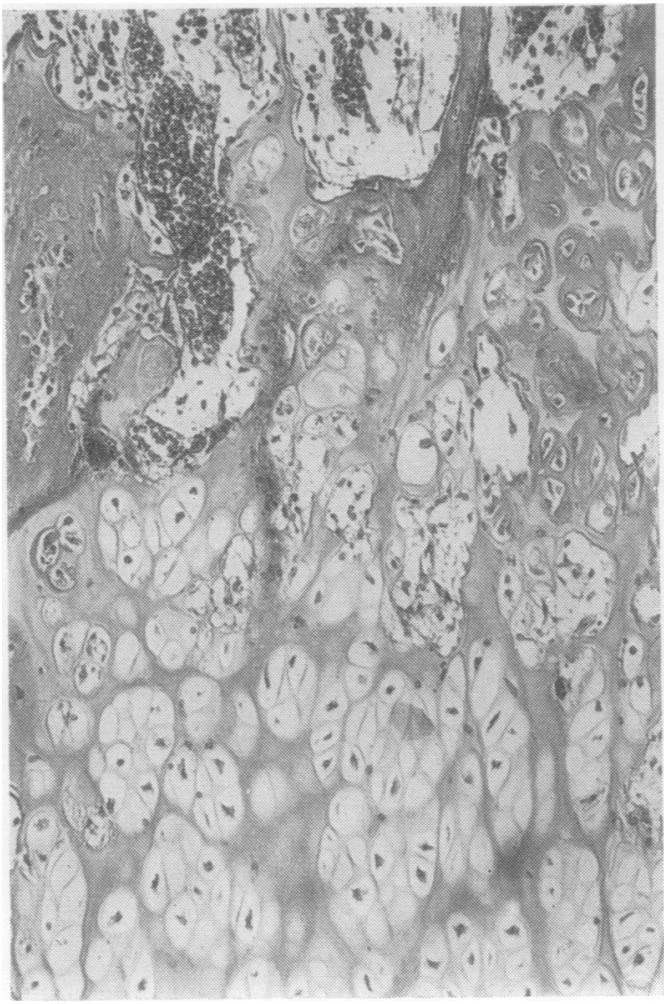

Fig. 4 The costochondral junction from case 1 whose liver is shown in Fig. 2 showing considerable growth arrest (Masson $\times 150)$.

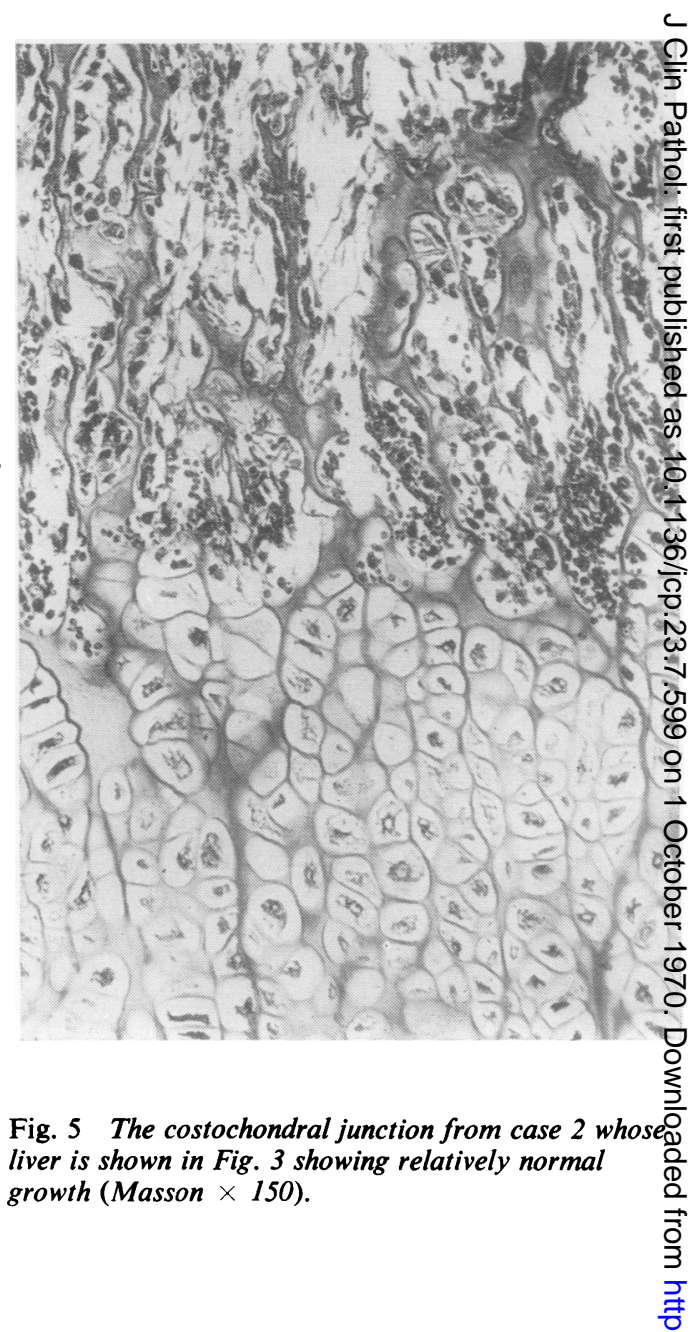

more than 60 minutes and they consider that permanent vascular changes are produced in the dog liver by ischaemia lasting more than 1.5 hours? Their work was concerned with problems of transplanting of livers: their experimental finding almost exactly mimic the changes seen in the human neonate.

Parker (1956), in a survey of livers in the files of Bernhard Baron Institute, found six instances. of what he described as congenital fibrosis of the liver. They were from patients of ages ranging from 1 hour after birth to 33 years, the latted having a carcinoma of the liver. Four of the casess had congenital cysts of the kidneys. The increase in collagen of the liver occurred without disturbe ing the normal lobular pattern and without cysto formation. His two adult cases had signs of portaf hypertension. He considers the condition to be $\mathrm{a}$ O form of congenital anomaly. In his cases, no attempt was made to quantitate the fibrous tissue? in the liver or to state in which lobe of liver the fibrosis occurred. It seems likely that he was dealing with a mixed group of conditions which include one or two of those discussed here. He stresses a feature that is common to the livers. studied here which is that the fibrosis is associate 
with no disturbance of the structure of the liver and that there is an absence of regeneration nodules.

In a survey of cases of portal hypertension, Kerr, Harrison, Sherlock, and Milnes-Walker (1960) describe 13 patients all under the age of 16 which they consider to be congenital hepatic fibrosis. They consider the latter to be a variant of congenital cystic disease. They also draw the distinction between this condition and postcirrhotic changes and they consider that the portal hypertension is due to a deficiency in the terminal branches of the portal vein. A further two cases of congenital hepatic fibrosis associated with portal hypertension occurring in siblings was described by Hardin (1965).

The findings of this study stress the importance of separate assessment of the left and right livers in children. The study also provides a quantitative background against which any types of fibrosis of the liver must be assessed.

Mr A. Tunstill prepared the photomicrographs.

\section{References}

Cantlie, J. (1897-1898). On a new arrangement of the right and left lobes of the liver. J. Anat., 32, iv-ix.

Emery, J. L. (1952). Degenerative changes in the left lobe of the liver in the newborn. Arch. Dis. Childh., 27, 558-561.

Emery, J. L. (1955). Asymmetrical liver disease in infancy. J. Path. Bact., 69, 219-224.

Emery, J. L. (1963). Functional asymmetry of the liver. Ann. N.Y. Acad. Sci., III, 37-42.

Emery, J. L., and Kalpaktsoglou, P. K. (1967). The costochondral junction during later stages of intrauterine life, and abnormal growth patterns found in association with perinatal death. Arch. Dis. Childh., 42, no. 221, 1-13.

Gruenwald, P. (1949). Degenerative changes in the right half of the liver resulting from intrauterine anoxia. Amer. J. clin. Path., 19, 801-813.

Hardin, C. A. (1965). Congenital hepatic fibrosis. Arch. Surg., 9, 884-886.

Healey, J. E., Jr. (1954). Clinical anatomic aspects of radical hepatic surgery. J. int. Coll. Surg., 22, 542-550.

Healey, J. E., Jr., and Schroy, P. C. (1953). Anatomy of the biliary ducts within the human liver. Arch. Surg., 66, 599-616.

Healey, J. E., Jr., and Sterling, J. A. (1963). Fragmental anatomy of the newborn liver. Ann. N.Y. Acad. Sci., III, 25-35.

Kerr, D. N. S., Harrison, C. V., Sherlock, S., and Milnes-Walker, R. (1961). Congenital hepatic fibrosis. Quart. J. Med., 30, 91-117.

Mall, F. P. (1906). A study of the structural unit of the liver. Amer. J. Anat., 5, 227-308.

Parker, R. G. F. (1956). Fibrosis of the liver as a congenital anomaly. J. Path. Bact., 71, 359-368.

Swenson, O., Grana, L., Inouye, T., and Donnellan. W. L. (1967). Immediate and long-term effect of acute hepatic ischaemia. Arch. Surg., 95, 451-463. 